\title{
Patient characteristics of children with cow's milk allergy presenting with an allergy to extensively hydrolyzed whey and/or casein formulae used as part of an elimination diet
}

\author{
Zygmunt Nowacki \\ Allergological-Pediatric Practice, Krakow, Poland \\ Head: Zygmunt Nowacki MD, PhD
}

Postep Derm Alergol 2012; XXIX, 6: 421-431 DOI: 10.5114/pdia.2012.32389

\begin{abstract}
Introduction: In the recent years the number of children with cow's milk protein allergy (CMPA) presenting with allergies to extensively hydrolyzed whey (eHF-W) and casein formulae (eHF-C) respectively has increased.

Aim: To present the patient characteristics of children with CMPA who presented with allergic reactions to eHF-W and/or eHF-C used as part of an elimination diet.

Material and methods: A retrospective study was carried out for a group of 65 selected from of 359 children ( 3 to 12 months) affected with CMPA and allergy to eHF.

Results: $18.1 \%$ (65/359) and 7.8\% (28/359) from the group presented with allergic reactions to eHF-W and eHF-C, respectively. An allergic reaction to eHF-C occurred in $43 \%$ of the patients from the group (28/65). IgE-mediated CMPA presented with one of the following clinical manifestations: atopic dermatitis (AD) $94 \%$, gastrointestinal symptoms (GI) 47\%, respiratory symptoms (RS) 44\%, anaphylactic reactions (AR) $26 \%$. Non-lgE-mediated CMPA, on the other hand, manifested with: AD 97\%, GI 22\%, RS 10\%.The observations showed that all 31 from the non-IgE mediated CMPA group with GI and AD manifestations presented with symptoms of eHF-C allergy $(p=0.001)$. In the IgE-mediated CMPA $(n=34)$ the following factors were statistically significant with relation to eHF-C allergy: CMPA manifesting with $\mathrm{GI}(p=0.014)$ and $\mathrm{AD}$. The occurrence of AR in response to cow's milk protein (CMP) decreased the probability of an eHF-C allergy $(p=0.028)$ in a statistically significant way.

Conclusions: Children with CMPA who presented with allergies to eHF-W and eHF-C had a higher frequency of clinical manifestation with $\mathrm{Gl}$ and $\mathrm{AD}$.
\end{abstract}

Key words: cow's milk allergy, elimination diet.

\section{Introduction}

Allergic conditions are currently one of the key issues in contemporary medicine. Studies conducted in Europe have shown that allergic hypersensitivity to food is a significant clinical problem with increasing prevalence [1].

A food allergy is defined as an adverse immune response to ingested food. It is not a disease in the classic sense, but rather a pathological reaction affecting numerous organs and tissues, which may present as atopic dermatitis (AD), urticaria, angioedema, asthma, allergic rhinitis, anaphylactic reaction (AR), or various gastrointestinal symptoms (GI) [2-4].
It is currently believed that in Europe ca. $7 \%$ of all children before the age of 3 are afflicted with this type of disorder $[5,6]$.

Cow's milk protein allergy (CMPA) is most frequently observed in infants and small children fed with modified milk or breast-fed children who are additionally bottlefed with modified milk, and affects ca. $4-8 \%$ of children [7-9]. Ca. 0.5\% of exclusively breast-fed children present with CMPA [10]. Hypersensitivity reactions to food may belong to any of the 4 types described by the Gell and Coombs classification. The most common response in people allergic to food is type I, immediate and IgE-mediated hypersensitivity reaction, which is responsible for

Address for correspondence: Zygmunt Nowacki MD, PhD, Allergological-Pediatric Practice, 7 Masarska St, $31-534$ Krakow, Poland, phone: +48 1242269 43, fax: +48 1241154 88, e-mail: zz.nowacki@gmail.com 
$48-52 \%$ of the observed symptoms. Cytotoxic reactions (type II), reactions mediated by immune complexes (type III) and delayed-type hypersensitivity reactions (type IV) are observed for ca. $6 \%, 10 \%$ and $18 \%$ of patients, respectively. In as many as $28 \%$ of cases with food allergies there is more than one reaction type involved [11].

Cow's milk protein allergy is a group of signs and symptoms that present after ingestion of foods containing CMP; it occurs mostly via IgE-mediated, non-IgE-mediated or mixed (IgE/non-lgE mediated) mechanisms [2, 12]. The signs and symptoms of CMPA are non-specific and vary considerably. The consumption of milk and milk products by individual patients may result in different clinical manifestations at different stages. Some of the reasons for these differences include the type of mechanism involved in the hypersensitivity reaction (immediate - IgE-mediated, delayed - non-IgE-mediated or mixed IgE/non-IgE mediated), as well as the reaction site $[10,13]$. The severity of an allergic reaction depends on the site of the disease process (single organ or multiple organs), among other things, and its course may vary from child to child. Cow's milk protein allergy most often manifests with cutaneous symptoms, while the next two most frequent manifestations are gastrointestinal symptoms (GI) and respiratory symptoms (RS). Its severity may be classified as mild, moderate or severe. Anaphylactic reaction and other forms and/or signs and symptoms are much less frequently observed [10].

A 2008 report by the Centers for Disease Control and Prevention (CDC) noted an 18\% increase in the prevalence of food allergy between 1997 and 2007, emphasizing the observed increase in the frequency of $A R$ in response to food consumption [14].

Bovine milk contains proteins that may induce allergic reactions. There are two main groups of bovine milk that are of clinical importance: casein proteins (Bos d8) and whey proteins ( $\alpha$-lactalbumin - Bos d4, $\beta$-lactoglobulin - Bos d5, bovine serum albumin - Bos $\mathrm{d} 6$, and bovine immunoglobulins - Bos d7). Bovine casein contains four types of proteins: $\alpha_{s 1}, \alpha_{s 2}, \beta, \kappa$. Patients are often allergic to the $\alpha$ - and $\kappa$-fractions of casein (100\% and ca. $91.7 \%$, respectively). Around $80 \%$ of patients with CMPA present with allergic reactions to bovine $\alpha$-lactalbumin [9]. According to medical standards making a proper diagnosis of food allergy requires a complex procedure. In addition to the medical history and the physical examination, the basic diagnostics include a number of tests carried out both in vitro and in vivo. Cow's milk protein allergy is mostly lgE-mediated, hence both the determination of the concentration of allergen-specific lgE (aslgE) in blood serum and the skin prick and skin application food tests (SPT and SAFT, respectively) may be of significant assistance in making the diagnosis. While tests measuring the aslgE level in blood serum and/or tests such as the SPT are valuable from a diagnostic viewpoint, they are not sufficient to diagnose food allergy [15]. The medical history, the clinical manifestation, and the test results will ultimately indicate which foods should be evaluated in open challenge tests or single-blind/double-blind placebo-controlled food challenges (SBPCFC/DBPCFC), and also indicate whether the challenge tests should be carried out on an inpatient basis and whether they should be postponed [10, 16].

A particular type of ingested food may be considered to be the sole cause of a condition only when its elimination from the diet causes the symptoms to disappear completely or relieves them to a considerable degree, while its reintroduction results in their recurrence. A successfully implemented elimination diet is an essential element of treatment. Therapeutic management of allergy is a consequence of its diagnostic and clinical complexity. The form of the elimination diet and its duration need to be adjusted to individual cases. Putting a patient on this type of diet should be justified by the medical interview, the clinical manifestation, and the results of tests and the specific food challenge tests performed (depending on the indications). Such an approach minimizes the associated risks. The ability to outgrow food allergies is related to the mechanism of hypersensitivity to food. Children with non-lgEmediated allergy outgrow food allergies sooner than children with IgE-mediated allergies [10]. The elimination diet constitutes the causal treatment of CMPA. Extensively hydrolyzed formulae (eHF) are recommended in the management of children fed with modified milk. In medical practice the two types of hydrolyzed formulae that are applied most often are extensively hydrolyzed whey formulae (eHF-W) and extensively hydrolyzed casein formulae (eHF-C). In recent years the incidence of failed treatment due to allergy to eHF given as part of an elimination diet has been growing significantly, and so has the unsubstantiated prescription of elimination diets [17-20].

\section{Aim}

The aim of the study was to present patient characteristics of children with allergies to CMP who presented with allergies to eHF-W and/or eHF-C used as part of an elimination diet.

\section{Material and methods Material}

The material for the study consisted of medical records of infants treated for CMPA. The analysis was retrospective in character. The initial group was selected from among 573 children diagnosed and treated at a Specialized Allergological Practice. Two hundred and fourteen children who had CMPA and were breast-fed or breast-fed and additionally given formulae containing eHF-W and eHF-C were excluded from further observations at the very outset. The final study group was selected via further exclusion of 294 children who were either successfully treated with the initially applied diet based on eHF-W or eHF-C or 
in whose case the observations of allergy to eHF were insufficient. A preliminary diagnosis of CMPA was made based on the medical history, the physical examination, the evaluation of signs and symptoms, and the identification of the food causing the reaction. The next diagnostic stage involved an elimination/challenge diagnostic diet and keeping a dietary record. Open challenge tests were performed after 3 to 8 weeks (depending on the initial symptoms) of the elimination/challenge diet. During these tests patients were given food (modified lactose-free milk) suspected of inducing the signs and symptoms in gradually increased doses. The recurrence of symptoms after repeated unintentional exposure to a food allergen was also considered a positive result of the challenge. The challenge tests were ordered to be carried out only under conditions in which anti-shock therapy was possible. The challenge test was not performed if the medical history indicated that food allergy may manifest as an anaphylactic reaction. The type of CMPA (i.e. IgE-mediated vs. non-lgE-mediated or IgE/non-IgE mediated) was diagnosed based on the clinical presentation over time and the results of aslgE tests. The clinical manifestation of CMPA and the family history of allergic conditions were established for all children. The final diagnosis was made when the correlation between the ingestion of a given food type and the presentation of signs and symptoms was confirmed.

A group of 65 children aged 3 to 12 months was selected for further analysis. The group included 25 females and 40 males. The basic inclusion criteria for the observations were the presentation of CMPA symptoms during the infant stage of children fed with modified milk and the occurrence of eHF-W allergy. Further observations were carried out for those children who were initially put on an eHF-W-based elimination diet (Bebilon Pepti - Nutricia) and who were then given eHF-C (Nutramigen - Mead Johnson Nutrition) due to the allergy-related failure of the initial treatment. The adverse finding - allergy - was made based on the medical history, the physical examination, and by applying the elimination diet for 4 weeks and then performing an open challenge test with the previously used eHF. Children who presented with an allergy to eHF-C received an amino acid formula (EleCare - Abbott Nutrition). All 65 children under observation had their total IgE (normal values of $t$-lgE for different age groups: before the age of 1: $0-29 \mathrm{IU} / \mathrm{ml} ; 1-2$ years old: $0-49 \mathrm{IU} / \mathrm{ml} ; 2-3$ years old: 0-45 $\mathrm{IU} / \mathrm{ml}$; 3-9 years old: $0-57 \mathrm{IU} / \mathrm{ml}$; over the age of 9: 0-89 $\mathrm{IU} / \mathrm{ml}$ ) and their aslgE levels determined; the latter parameter was determined for $\alpha$-lactalbumin, $\beta$-lactoglobulin, bovine casein, hen's egg white, and wheat by means of the IMMULITE $20003 \mathrm{~g}$ Allergy TM method (normal values expressed in kU/l: class 0: < 0.35 ; class 1: 0.35 0.69; class 2: 0.7-3.4; class 3: 3.5-17.4; class 4: 17.5-49.9; class 5: 50.00-100.00; class 6: > 100).

For further analysis the group of 65 children was divided into two subgroups:

I. Children with non-IgE-mediated CMPA (31 patients),
II. Children with IgE-mediated CMPA (34 patients).

Eight children with mixed (IgE/non-lgE mediated) CMPA were evaluated as part of the IgE-mediated group.

\section{Methods}

In the first group of children (non-IgE-mediated CMPA) the correlation between eHF-C tolerance (success = no allergic reaction; failure = allergic reaction) and other qualitative variables (gender, family history of allergic conditions, cutaneous, respiratory and gastrointestinal symptoms) was analyzed using Fisher's exact test and the $\chi^{2}$ test. In the second group (IgE-mediated CMPA) the correlation between eHF-C tolerance (success $=$ no allergic reaction; failure $=$ = allergic reaction) and other qualitative and quantitative variables was investigated using logistic regression ( $\mathrm{Cl}$ - confidence interval, OR - odds ratio). The levels of aslgE observed in the group tolerant to eHF-C and in the group presenting with eHF-C allergy were compared by means of the Mann-Whitney $U$ test. Two comparisons of aslgE antibody levels were carried out. In the first comparison all children from the IgE-mediated CMPA group were considered and the differences between the food-specific antibody levels observed for children on the diet based on eHF-C (success $=$ no allergic reaction to eHF-C) and for children on the AAF-based diet (failure = allergic reaction to eHF-C). The second comparison of aslgE levels excluded the children who had presented with an anaphylactic reaction (AR).

\section{Statistical analysis}

Statistical analyses were performed using the Statistica computer program (version 9.0).

\section{Results}

In the initial group of 359 children allergic reactions to eHF-W and eHF-C were observed in 18.1\% (65/359) and 7.8\% (28/359) of cases, respectively. Of the 65 children from the main study group, 28 presented with an eHF-C allergy, which amounts to $43 \%$. The proportions for the nonIgE-mediated CMPA and the IgE-mediated CMPA groups were $45 \%$ (14/31) and 41\% (14/34), respectively. No allergic reactions to $A A F$ and no $A R$ in response to eHF were observed in patients from the study group (Table 1).

The clinical manifestation involved multiple organs in $62 \%$ of patients from the study group. No anaphylactic reactions to either eHF-C, eHF-W or AAF were observed.

However, anaphylactic reactions to CMP occurred in $26 \%$ of the patients (9/34) from the IgE-mediated CMPA group (Table 2).

Fisher's exact test revealed that the efficacy of eHF-C in the first subgroup of patients (IgE-mediated CMPA) is not affected by such parameters as gender $(p=0.47)$, family history of allergic conditions ( $p=0.27)$, occurrence of $\mathrm{AD}(p=0.45)$ and respiratory symptoms $(p=0.58)$. The efficacy of eHF-C was, however, related to Gl symptoms 
Table 1. Clinical manifestations of CMPA, family history of allergic conditions, and the type of diet in the studied group of 65 patients

\begin{tabular}{lccccccccc}
\hline Variables & $\begin{array}{c}\text { Female } \\
{[\%]}\end{array}$ & $\begin{array}{c}\text { Male } \\
{[\%]}\end{array}$ & $\begin{array}{c}\text { AD } \\
{[\%]}\end{array}$ & $\begin{array}{c}\text { Gl } \\
{[\%]}\end{array}$ & $\begin{array}{c}\text { RS } \\
{[\%]}\end{array}$ & $\begin{array}{c}\text { AR } \\
{[\%]}\end{array}$ & $\begin{array}{c}\text { Family history } \\
\text { of allergic } \\
\text { conditions [\%] }\end{array}$ & $\begin{array}{c}\text { eHF-C- } \\
\text { based } \\
\text { diet [\%] }\end{array}$ & $\begin{array}{c}\text { AAF- } \\
\text { based } \\
\text { diet [\%] }\end{array}$ \\
\hline Study group $(n=65)$ & 38 & 62 & 95 & 35 & 28 & 14 & 65 & 57 & 43 \\
\hline $\begin{array}{l}\text { IgE-mediated CMPA } \\
\text { subgroup }(n=34)\end{array}$ & 32 & 68 & 96 & 47 & 54 & 26 & 70 & 59 & 41 \\
\hline $\begin{array}{l}\text { Non-IgE-mediated } \\
\text { CMPA subgroup }(n=31)\end{array}$ & 45 & 55 & 94 & 22 & 10 & 0 & 58 & 55 & 45 \\
\hline
\end{tabular}

$A D$ - atopic dermatitis, GI - gastrointestinal symptoms, RS - respiratory symptoms, AR-anaphylactic reaction

Table 2. Significant data concerning the group of 9 children who presented with anaphylactic reactions to CMP: average concentration of total IgE (t-lgE), average concentration of allergen-specific IgE for $\alpha$-lactalbumin (ALA), $\beta$-lactoglobulin (BLG), bovine casein, egg white and wheat, and finally type of diet and gender distribution

\begin{tabular}{lccccccccc}
\hline $\begin{array}{l}\mathrm{t}-\mathrm{IgE} \\
{[\mathrm{IU} / \mathrm{ml}]}\end{array}$ & $\begin{array}{c}\mathrm{ALA} \\
{[\mathrm{kU} / \mathrm{l}]}\end{array}$ & $\begin{array}{c}\mathrm{BLG} \\
{[\mathrm{kU} / \mathrm{l}]}\end{array}$ & $\begin{array}{c}\text { Casein } \\
{[\mathrm{kU} / \mathrm{l}]}\end{array}$ & $\begin{array}{c}\text { Egg } \\
{[\mathrm{kU} / \mathrm{l}]}\end{array}$ & $\begin{array}{c}\text { Wheat } \\
{[\mathrm{kU} / \mathrm{l}]}\end{array}$ & $\begin{array}{c}\text { eHF-C- } \\
\text { based } \\
\text { diet }[\%]\end{array}$ & $\begin{array}{c}\text { AAF- } \\
\text { based } \\
\text { diet [\%] }\end{array}$ & $\begin{array}{c}\text { Female } \\
{[\%]}\end{array}$ & $\begin{array}{c}\text { Male } \\
{[\%]}\end{array}$ \\
\hline 496.5 & 46.3 & 28.1 & 64.3 & 51.2 & 13.6 & 89 & 11 & 45.5 & 55.5 \\
\hline
\end{tabular}

( $p=0.001)$. All children in this group showing CMPA-related Gl symptoms also presented with symptoms of eHF-C allergy, and, in addition, symptoms of AD.

Logistic regression was used to evaluate the dependence of eHF-C efficacy on other qualitative and quantitative variables in the second subgroup (IgE-mediated CMPA). This analysis yielded the following conclusions: - The occurrence of CMPA-related GI symptoms is associated with a statistically significant increase in the probability of eHF-C allergy: $p=0.014, \mathrm{OR}=20.3,95 \% \mathrm{Cl}$ : 3.9-105.6.

- TThe occurrence of an anaphylactic reaction is associated with a statistically significant decrease in the probability of eHF-C allergy: $p=0.028, \mathrm{OR}=0.028,95 \% \mathrm{Cl}$ : 0.002-0.396

The probability and chance of failure (allergic reaction to eHF-C) and success (no allergic reaction to eHF-C) were calculated as part of further analysis based on the parameters of the logistic regression model.

The 11 patients who presented with CMPA-related GI symptoms and in whom no anaphylactic reaction occurred were allergic to eHF-C more often than the other children. The probability of an eHF-C allergy in this group was very high and equal to 0.82 . The group with no GI symptoms and no anaphylactic reaction had a much lower probability of 0.28 . It should also be emphasized that the group of 11 children ( 3 females and 8 males) at most risk (i.e. the patients with $\mathrm{Gl}$ symptoms and no anaphylactic reaction) constitutes $32 \%$ of the second subgroup (34 patients).

In the course of subsequent analysis the t-IgE levels and the concentration of aslgE antibodies (allergens: $\beta$-lactoglobulin, casein, $\alpha$-lactalbumin, hen's egg white) observed for individual patients from the second subgroup with IgE-mediated CMPA were compared. These levels were compared twice for children with good tolerance to eHF-C (success - no allergic reactions to eHF-C) and children receiving an AAF due to eHF-C allergy. The first comparison included all children from the IgE-mediated CMPA subgroup and analyzed the differences between antibody levels in children tolerant to eHF-C and in children who are allergic to it, i.e. children on the AAF-based diet. The second comparison of antibody levels excluded the children who had presented with an anaphylactic reaction.

The 25 children in the case of whom failure (eHF-C allergy) was observed had statistically significant higher t-lgE levels and higher concentrations of aslgE antibodies (allergens: $\beta$-lactoglobulin, casein, $\alpha$-lactalbumin, hen's egg white) than did children tolerant to the diet based on eHF-C (Figure 1).

During further analysis the relevant parameters for those children from the IgE-mediated CMPA group who did not present with AR were compared. All aslgE results pertaining to bovine milk allergens ( $\beta$-lactoglobulin, casein, $\alpha$-lactalbumin) and above normal range (i.e. aslgE values $\geq 0.7 \mathrm{kU} / \mathrm{l}$ ) were analyzed for a group of 12 children with good tolerance to the diet based on eHF-C (success $=$ no allergic reaction to eHF-C) and a group of 13 children who had been receiving AAF due to an eHF-C allergy. The levels of antibodies were compared twice, and the number of positive aslgE results ( $\geq 0.7 \mathrm{kU} / \mathrm{l})$ for specific allergens was established for each child from both groups. The majority of the 13 children in the group with the AAF-based diet have above-normal concentrations of aslgE antibodies ( $\geq 0.7 \mathrm{kU} / \mathrm{l}=$ class 2$)$ for either two or three bovine milk 

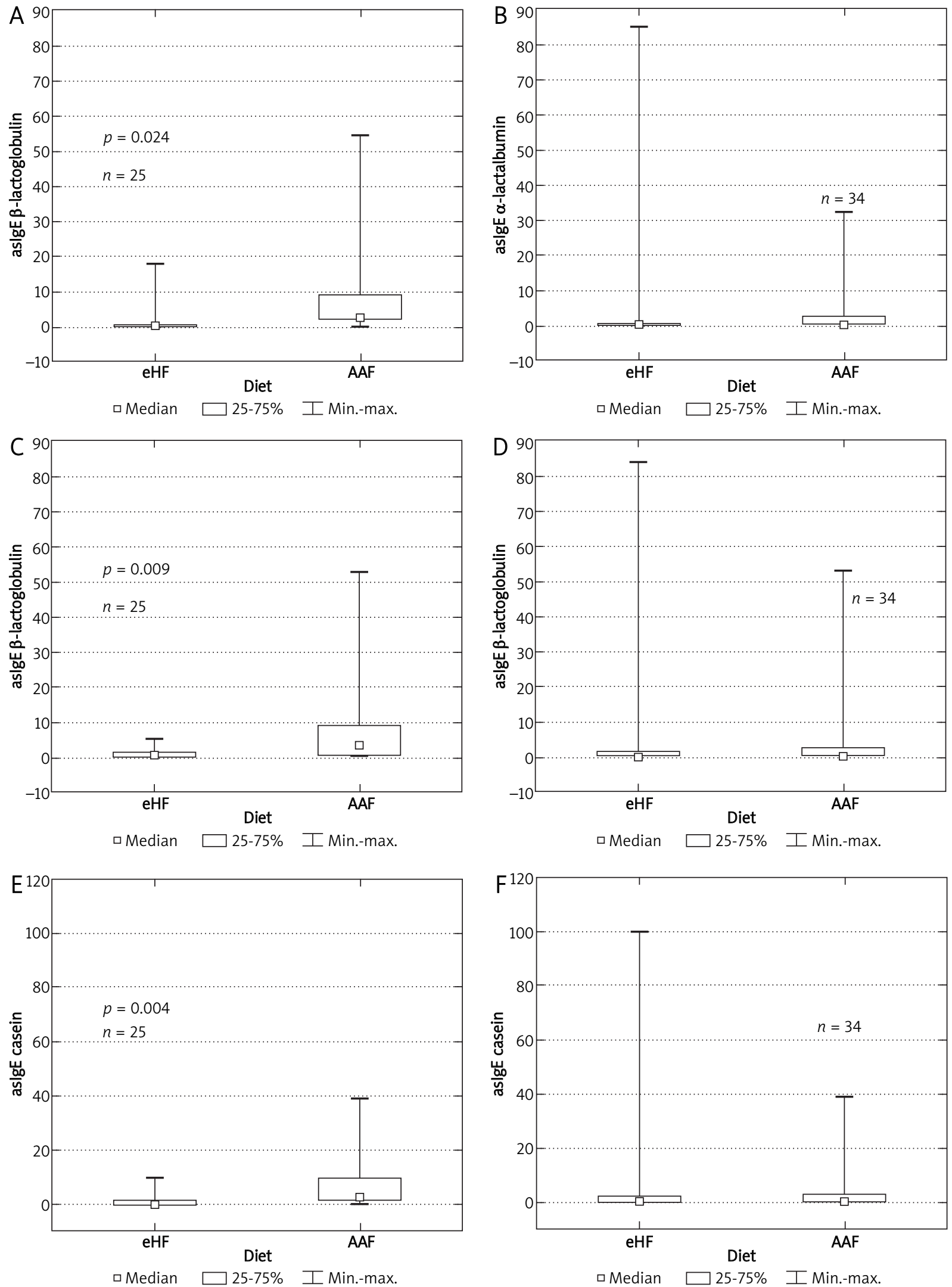

Figure 1. Results of the Mann-Whitney U test - level of aslgE antibodies in children with IgE-mediated allergy vs. type of diet. The right-hand side of the diagram represents the data for all children in this group $(n=34)$, including those who presented with an AR, while the left-hand side represents only those children in whom no AR was observed $(n=25)$ 

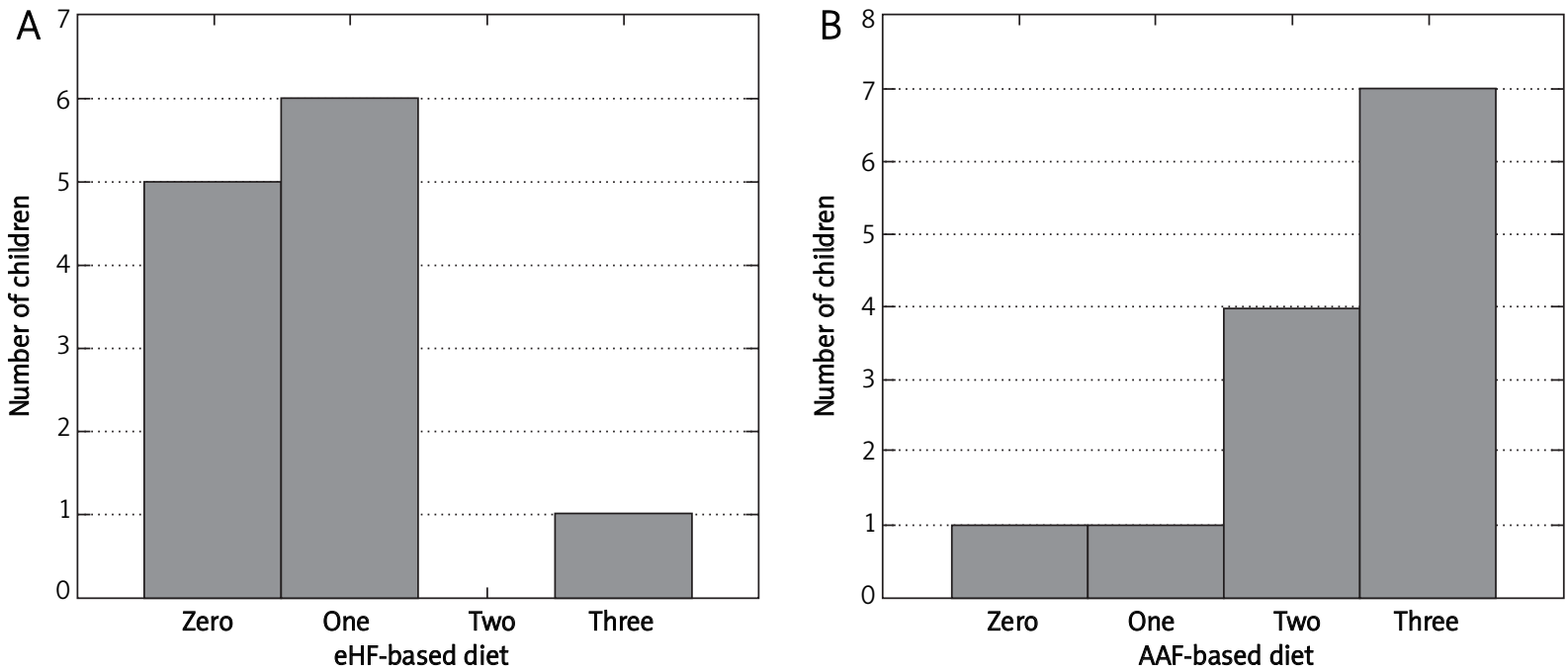

Figure 2. Concentration of aslgE antibodies for allergens: casein, $\alpha$-lactalbumin, $\beta$-lactoglobulin - number of values $\geq 0.7 \mathrm{kU} / \mathrm{l}$ (above normal range) in a group of 25 children with IgE-mediated CMPA who did not present with an anaphylactic reaction, as observed for each type of diet (AAF-based vs. eHF-C-based)

allergens (30.77\% and $53.85 \%$ of patients, respectively). These children account for over $80 \%(53.85+30.77 \%)$ of the AAF group. On the other hand, the majority of children in the eHF-C group had either a single aslgE result $\geq 0.7$ kU/l (50.0\%) for one bovine milk allergen or no positive results at all (41.67\%). These children accounted for $90 \%$ of this group $(41.67+50.00 \%)$.

There is a correlation between the occurrence of eHF-C allergy and the number of values of aslgE for individual bovine milk allergens equal to or greater than $0.7 \mathrm{kU} / \mathrm{l}$; this correlation was confirmed using the $\chi^{2}$ test $(p=0.002)$. Two or three aslgE values above the normal range were more common among children allergic to eHF-C than among non-allergic children (Figure 2).

\section{Discussion}

The first accounts concerning allergy-related treatment failure when using elimination diets based on hydrolyzed soy formulae (HSF), eHF-W and eHF-C were reported in the 1980s and 1990s [21, 22].

In the group initially under observation, allergies to eHF-W and eHF-C were present in 18.1\% (65/359) and 7.8\% (28/359) of patients, respectively. The prevalence of these allergies in the present study is consistent with the value reported in the currently available literature, i.e. ca. 10\% [23-25].

In the study by Kaczmarski et al. 67 cases of children with AD were investigated. Treatment failure - allergy to eHF - was observed in $32.8 \%$ (22/67) of patients. Of these 22 patients, 17 were allergic to eHF-C, 4 were allergic to eHF-W and one presented with an allergy to AAF [26]. A study by Finnish authors Klemola et al. reported an eHF-W incidence of 2.2\% [27].
This type of allergy to eHF is likely a much more common phenomenon than believed so far. In clinical practice the first-line treatment of infants with CMPA-related cutaneous symptoms (AD) usually involves eHF. In some cases the prescription of an eHF-based diet results in a temporary improvement lasting several days, after which there is a relapse of the previously observed signs and symptoms. At this stage the most widely applied management of the condition involves intensifying the treatment of the cutaneous symptoms and waiting for the patient to outgrow the allergy. However, this approach (i.e. ignoring the cause-and-effect relationship between the type of ingested food and the signs and symptoms, and the continuation of an eHF-based diet) seems unreasonable. It is likely due to the lack of consensus on the treatment of $A D$ between researchers specializing in pediatric allergology and dermatologists. Many authors have been highlighting this problem for a long time [28, 29].

The approach to management in the present study entailed the transition from eHF-W to eHF-C in those children who presented with an allergy to the former (failure of treatment). However, $43 \%$ of patients presented with eHF-C allergy after the transition, with similar incidence rates in the IgE-mediated and mixed CMPA group (41\%) and the non-lgE-mediated CMPA group (45\%). This approach is therefore very likely to fail regardless of the mechanism underlying the allergic reaction. The results of these observations cannot be directly compared to those obtained in any other study, since no studies that were similar in design (i.e. studies in which one unsuccessfully used eHF type was replaced with another type, e.g. eHF-W with eHF-C) were found. This approach to management, common in pediatric practice, was the result of the limited availability of AAF in Poland. Experts most often suggest that 
AAF should be applied in cases of allergies to any one of the extensively hydrolyzed formulae that are confirmed by elimination and challenge tests, and in cases of severe allergies affecting multiple organs and presenting with gastrointestinal symptoms (enteropathy, malabsorption) and AR $[2,17,20]$.

In the observed group CMPA manifested most frequently as AD and GI symptoms (Table 1). The literature on the subject has been drawing attention to the change in clinical manifestation of CMPA for many years now. In a 1951 study Clein observed 140 infants. Cutaneous, gastrointestinal and respiratory symptoms of CMPA were present in $43 \%, 51 \%$ and $10 \%$ of individuals, respectively [30]. Gerrard et al., Hill et al., and Kaczmarski made similar observations in the 1960s, 1970s, and 1980s [31-33]. The studies carried out by these authors found GI symptoms to be the predominant manifestation of CMPA. On the other hand, recent reports confirm that the cutaneous manifestation is the most frequently observed manifestation of CMPA [5]. There are two possible explanations of this phenomenon. On the one hand, it might be a consequence of changes in feeding patterns and/or the level of the parents' knowledge and/or the availability of tests that enable early diagnosis of allergy. On the other hand, it may mean that the gastrointestinal manifestation of CMPA is transforming and becoming asymptomatic like celiac disease, the latent/occult variant of which provides an illustration of this possibility [34]. That is why the clinical manifestation of CMPA is increasingly often analyzed in the context of the underlying immune mechanism. In their paper, Hill et al. reported that in their study 100 children (27\%) developed a cutaneous manifestation in the form of urticaria and angioedema after 45 min. Fifty percent of children presented with emesis and diarrhea. After more than $20 \mathrm{~h}$ had elapsed AD was observed in $20 \%$ of subjects [35]. The proportion of children with a given clinical manifestation was thus clearly dependent on the type of hypersensitivity reaction (IgE-mediated, non-IgE-mediated or IgE/nonIgE mediated). It is therefore reasonable to suggest that all collective reports should contain additional information on the immune mechanism underlying CMPA for the patients included in the corresponding studies [10, 20].

The lgE-mediated mechanism was observed most often in the case of gastrointestinal or respiratory manifestation, while the non-lgE mechanism was associated with the cutaneous manifestation of CMPA. The relationship between the immune mechanism of hypersensitivity reactions and the clinical manifestation and family history of allergic conditions observed in the present study is similar to that reported in the literature [36-38].

In the IgE-mediated CMPA group (34 patients) an AR occurred in $26 \%$ of children (Table 2 ). In the literature this type of clinical manifestation of CMPA is estimated to occur in $4-15 \%$ of cases, with a noticeable upward trend [39, 40]. Eight of the children who presented with an AR to CMP were maintained on a diet based on eHF-C. This group was char- acterized by high average t-lgE and aslgE concentrations (Table 2). Many studies have evaluated the factors (gender, atopy, aslgE for particular foods) that may be used to predict the severity of the subsequent allergic reaction. The available literature has shown that higher concentrations of aslgE correlate with increased probability of an allergic reaction after food ingestion, but do not directly affect its severity. It should be emphasized that aslgE levels may be determined using different methods [41-43].

It has also been shown that people suffering from asthma are at a higher risk of developing an anaphylactic reaction and that the incidence of these reactions is the same for both sexes [44].

A study by Spanish authors Boyano-Martinez et al. evaluated the consequences of unintentional ingestion of CMP for children allergic to this allergen. Eighty-eight children participated in the study, and the observations lasted 12 months. Thirty-five children developed allergic reactions, and $15 \%$ presented with severe symptoms. The risk of presenting with severe symptoms was associated with a high concentration of aslgE and asthma [45].

A study by Celik-Bilgili et al. evaluated the level of aslgE in 501 children (average age of 13 months). All children had their specific lgE serum concentration determined and they were all subjected to food challenge tests. A correlation between the aslgE concentration and the positive result of oral challenges with CMP and chicken eggs was demonstrated [46].

The literature features many reports that stress the fact that a high level of aslgE for casein and multiple organ manifestation of CMPA are both factors that increase the risk of developing an allergy to eHF [47, 48]. The observations made in the present study contradict those by other authors, since the analysis of the level of aslgE antibodies would suggest the opposite correlation. As can be seen in the presented diagrams (Figure 1), the children who developed anaphylactic reactions did not present with the clinical symptoms of eHF-C allergy, despite having very high levels of aslgE, but they were allergic to eHF-W. However, after the exclusion of children with AR and the subsequent comparison of aslgE levels, the observations were consistent with those by other authors. In the investigated group with IgE-mediated CMPA (25 children) patients who were allergic to eHF had statistically significant higher levels of t-lgE and aslgE antibodies (allergens: $\beta$-lactoglobulin, casein, $\alpha$-lactalbumin, hen's egg white, wheat) than patients who tolerated the diet based on eHF-C. This observation was consistent with the literature reports for this age group, provided the children with anaphylactic reactions were excluded $[43,44]$. Without this exclusion, the aslgE levels for casein indicate the opposite correlation. Two or three results above the normal range, i.e. those that were equal to or greater than $0.7 \mathrm{kU} / \mathrm{l}(p=0.02)$, were observed more often for children from the group with eHF-C allergy than for other children. In a study by Kaczmarski et al. it was observed that the results for $\beta$-lactoglobulin, casein 
and $\alpha$-lactalbumin are positive (aslgE $\geq 0.7 \mathrm{kU} / \mathrm{l}$ ) more often for children with multiple organ manifestation and $A D$ than for allergic children with GI symptoms [49]. The following question arises: was the fact that children with CMPA who developed AR did not show the symptoms of allergy to eHF-C merely a coincidence related to the small size of this group, or was it an indicator of the occurrence of AR in a group of children with different genetic and immunological characteristics? It might have been caused by the clinical variability associated with the age at which the diet was prescribed, and/or with biological and/or genetic variation in this group of patients. Fisher's exact test revealed that in the group with non-IgE-mediated CMPA allergy to eHF-C was not dependent on variables such as gender, family history of allergic conditions, or cutaneous and respiratory symptoms. The factor associated with eHF allergy was CMPA-related gastrointestinal symptoms $(p=0.001)$. All children in this group with a GI manifestation of CMPA presented with an allergy to eHF, as well as AD. The literature dealing with this issue has been reporting multiple clinical manifestations in a single child for many years now [2]. Even though a similar group of protein allergens is the causal factor in every case of CMPA, the clinical response of a child's body, i.e. the clinical manifestation, is different for each patient. The site affected by the allergic reaction and the underlying immune mechanism determine the severity of the process, and are always unique and variable with age [10].

Hill et al. evaluated the efficacy of AAF in a systematic review. They analyzed 20 investigations, in which eHF and/or AAF were used. In the case of children with the nonIgE-mediated form of allergy, in whom CMPA manifested with $\mathrm{Gl}$ symptoms or $\mathrm{AD}, \mathrm{AAF}$ were more effective than eHF [49].

Although medical knowledge is constantly being expanded, as of today we are still unable to predict with a high degree of certainty whether a given patient with CMPA will necessarily develop an allergy to eHF. There are no sufficiently reliable tests with the required specificity and sensitivity that would make it possible to unambiguously diagnose and/or predict this form of hypersensitivity. We still do not know whether the mechanism underlying the symptoms of eHF allergy is an IgE-mediated, non-IgE-mediated or mixed one, or whether children with the IgE-mediated CMPA, for example, develop an eHF allergy with the same underlying mechanism.

Even new diagnostic techniques do not provide the desired evidence in eHF food allergies, since aslgE antibodies may be undetectable in blood serum when their specificity is limited to epitopes undergoing modification or forming de novo during the processing of food and/or digestion and/or in the case of a cross-allergy to eHF.

Children may also react to residual allergens present in eHF [10]. Furthermore, most affected children may also possibly present with reactions to more than one allergen that is formed de novo in the Gl tract. The widely applied commercial tests that determine the level of aslgE antibodies for $\beta$-lactoglobulin, casein and $\alpha$-lactalbumin, however, may only be used to detect antibodies against the allergens present in the native food material, and not in the eHF. The IgE-mediated and non-IgE-mediated pathogenic mechanisms are often complex in practice. Assuming that the eHF allergy is a form of cross-allergy, the possibility that cross-hypersensitivity occurs mostly via the IgE-mediated mechanism should be considered. This phenomenon is determined mainly by the structure of the so-called major antigens, which are recognized by the immune system and stimulate the synthesis of specific lgE antibodies. A cross-reaction is highly probable, as the homology of protein sequences may be as high as $70 \%$; for values lower than $50 \%$ cross-reactions are observed very infrequently [50]. A cross-reaction may occur when aslgE antibodies against a given allergen recognize it and bind to similar protein from a different source. In terms of epitopes, this protein is characterized by a high degree of similarity or may even be identical. The discoveries of the structure of allergens and of the T-cell receptor (TCR), the introduction of the notion of epitope, and the development of new diagnostic techniques (e.g. immunoblotting) all made it possible to partially understand the pathophysiology of cross-allergies [51]. An allergy that is a result of cross-reacting foods is a very difficult problem from a diagnostic standpoint. The assessment of these reactions requires the application of suitable research methods. These methods should combine the analysis of individual proteins responsible for cross-reactions (both those contained in eHF and those forming de novo, as well as those found in various allergen extracts) with the simultaneous assessment of the antibodies contained in the investigated sera. In the future the diagnosis of allergy to eHF should be confirmed by means of tests utilizing recombinant allergens and new diagnostic techniques such as immunoblotting or ImmunoCAP ISAC (Immuno Solid-Phase AllergoChip) [52-58]. When deciding on which additional tests should be ordered it should therefore be kept in mind that hypersensitivity reactions to eHF have an unknown IgE-mediated, non-lgE-mediated or mixed underlying mechanism. Hence, it cannot be ruled out that patients who have IgEmediated CMPA may develop a non-lgE-mediated or mixed eHF allergy. In spite of convincing symptoms of the condition that provide information as to the possible mechanism, in many cases circulatory aslgE remain undetected. The results of the 2011 study by Söderström et al. suggest that lowering the aslgE detection threshold in small children is justified [59].

Performing cutaneous tests with eHF, such as skin prick tests (SPTs, in this case prick-by-prick tests, to be precise), skin application food tests (SAFTs), or patch skin tests (PSTs), in the course of the present study was often impossible due to the extent and severity of AD symptoms or other technical issues related to the age of the children undergoing diagnosis. Nor can the results of prick-by-prick, PST 
or SAFT tests for eHF be compared directly, as their standardization poses a considerable difficulty; clinicians are thus forced to conduct a challenge test that will confirm or rule out eHF allergy anyway [23,60].

So far our observations may only be based on the time elapsed between eHF ingestion and the presentation of symptoms. Consequently, both skin tests (SPT, SAFT) and the determination of aslgE levels in blood serum may play a rather insignificant role in the diagnosis of eHF. So far positive and negative predictive values (PPV and NPV) find application only in the diagnostics of CMPA $[2,61]$, as is the case with cellular activation tests, the histamine release microfiber method (HR-MM), the cellular antigen stimulator test (CAST-ELISA) or the basophil activation test (BAT) with CD63 and CD203c molecules - all used in the diagnosis of the non-IgE-mediated immune mechanism [62-64]. When suspecting allergy to eHF a challenge test should therefore be carried out. However, this test is often not performed, since the parents, who witness major improvements in the child's condition after the introduction of AAF into the diet, refuse to let the child be subjected to a challenge with eHF. In these situations the diagnosis ex juvantibus principle is followed [20]. Therapeutic management is a consequence of the fact that allergy to eHF poses a complex clinical and diagnostic problem. In this clinical context the type of elimination diet, its extent, and its duration need to be highly individualized $[2,20,39]$. It is furthermore important to confirm the need for its prescription beforehand based on the medical history, the clinical picture, the available tests, and food challenge tests (depending on the indications). This approach decreases the risk of the unjustified prescription of an elimination diet [17, 20, 30]. The ability to outgrow allergies is dependent on the mechanism of the hypersensitivity reaction to food. Children exhibiting non-lgEmediated intolerance outgrow food allergies sooner than those who display an IgE-mediated mechanism [2]. Genetic engineering and molecular allergology offer new diagnostic possibilities. These methods make it possible to obtain recombinant antigens on an industrial scale. The establishment of the molecular structure of allergenic protein will probably make it possible to determine which single molecules present in the native eHF allergenic material are the most allergy-inducing. These techniques might also make it possible to carry out detailed identification and determination of specific allergen fractions in compound mixtures, or to identify antibodies bound to cleft material by means of antiglobulin antibody markers $[65,66]$. These methods will likely provide more precise diagnostic pointers. Even though we do not have these methods at out disposal in basic allergological diagnostics, they are used in scientific applications. Discoveries in the fields of molecular biology and physics have always been followed by the development of increasingly non-allergenic therapeutic preparations to be used in the treatment of food allergy [67-69].
In summary, it should be noted that predicting allergies to eHF (in terms of probability) and/or diagnosing eHF allergies is a very complex process, which should be based on careful analysis at each stage of clinical studies and observations. As of today there are no sufficiently reliable tests with the required specificity and sensitivity that would make it possible to unambiguously predict an eHF allergy; nor are the data gathered from patient history sufficient. The clinical picture of CMPA manifestation and in vivo and in vitro diagnostic tests for this allergy do not yet provide an unambiguous answer to the following question: which elimination diet (elemental formulae-based vs. eHF-based) should be initially prescribed to which children?

\section{Conclusions}

Children with IgE-mediated, non-IgE mediated and IgE/non-IgE mediated (mixed) CMPA who were allergic to eHF-W and eHF-C presented with symptoms of GI disturbance and atopic dermatitis in response to CMP. Children with CMPA who present with allergic reactions to $\mathrm{HHF}-\mathrm{W}$ should receive AAF, since the transition from eHF-W to eHF-C therapy is very likely to fail. The efficacy of eHF-C in children presenting with CMPA-related anaphylactic reactions requires further investigations.

\section{References}

1. McBride D, Keil T, Grabenhenrich L, et al. The EuroPrevall birth cohort study on food allergy: baseline characteristics of 12000 newborns and their families from nine European countries. Pediatr Allergy Immunol 2011; 23: 230-9.

2. Sampson HA. Update on food allergy. J Allergy Clin Immunol 2004; 113: 805-19.

3. Karakis GP, Sin B, Tutka H, et al. Genetic aspect of venom allergy: association with HLA class I and class II antigens. Ann Agric Environ Med 2010; 17: 119-23.

4. Perez-Badia R, Rapp A, Morale C, et al. Pollen spectrum and risk of pollen allergy in central Spain. Ann Agric Environ Med 2010; 17: 139-51.

5. Steinke M, Fiocchi A, Kirchlechner V, et al. Perceived food allergy in children in 10 European nations. Int Arch Allergy Immunol 2007; 143: 290-5.

6. Kasznia-Kocot J, Kowalska M, Górny RL, et al. Environmental risk factors for respiratory symptoms and childhood asthma. Ann Agric Environ Med 2010; 17: 221-9.

7. Rona RJ, Keil T, Summers C, et al. The prevalence of food allergy: a meta-analysis. J Allergy Clin Immunol 2007; 120: 638-46.

8. Isolauri E, Tahvanainen A, Peltola T, et al. Breast-feeding of allergic infants. J Pediatr 1999; 134: 27-32.

9. Fiocchi A, Schünemann HJ, Brozek J, et al. Diagnosis and Rationale for Action Against Cow's Milk Allergy (DRACMA): a summary report. J Allergy Clin Immunol 2010; 126: 1119-28.

10. Vandenplas Y, Koletzko S, Isolauri E, et al. Guidelines for the diagnosis and management of cow's milk protein allergy in infants. Arch Dis Child 2007; 92: 902.

11. Chandra RK, Gill B. Food allergy and atopic disease: pathogenesis, diagnostic, prediction. Ann Allergy 1993; 71: 495-502. 
12. Korzon-Burakowska A, Dziemidok P. Diabetic foot - the need for comprehensive multidisciplinary approach. Ann Agric Environ Med 2011; 18: 314-7.

13. Wolańczyk-Medrala A, Barg W, Radlińska A, et al. Food-dependent exercise-induced anaphylaxis-sequence of causative factors might be reversed. Ann Agric Environ Med 2010; 17: 315-7.

14. Branum AM, Lukacs SL. Food allergy among U.S. children: trends in prevalence and hospitalizations. NCHS 2008; 10: $1-8$.

15. Fiocchi A, Bouygue GR, Albarini M, et al. Molecular diagnosis of cow's milk allergy. Curr Opin Allergy Clin Immunol 2011; 11: 216-21.

16. Kupczyk K, Adamska I, Swincow G, Czerwionka-Szaflarska M. Evaluation of double-blind, placebo-controlled food challenge (DBPCFC) value in confirmation of tolerance to cow milk preliminary trial. Postep Derm Alergol 2010; 27: 269-74.

17. Food Allergy in Children and Young People: Diagnosis and Assessment of Food Allergy in Children and Young People in Primary Care and Community Settings. Centre for Clinical Practice at NICE (UK). London, National Institute for Health and Clinical Excellence (UK), 2011, www.nice.org.uk/guidance/ CG116.

18. Pyrhönen K, Näyhä S, Kaila M, et al. Occurrence of parentreported food hypersensitivities and food allergies among children aged 1-4 yr. Pediatr Allergy Immunol 2009; 20: 328-38.

19. Burks AW, Jones SM, Boyce JA, et al. NIAID-sponsored 2010 guidelines for managing food allergy: applications in the pediatric population. Pediatrics 2011; 128: 955-65.

20. Kaczmarski M, Wasilewska J, Jarocka-Cyrta E, et al. Polish statement on food allergy in children and adolescents. Postep Derm Alergol 2011; 5: 331-67.

21. Hill DJ, Ford RP, Shelton MJ Hosking CS. A study of 100 infants and young children with cow's milk allergy. Clin Rev Allergy 1984; 2: 125-42.

22. Businco L, Cantani A, Longhi MA, Giampietro PG. Anaphylactic reactions to a cow's milk whey protein hydrolysate (Alfa-Ré, Nestlé) in infant with cow's milk allergy. Ann Allergy 1989; 62: 333-5.

23. de Boissieu D, Dupont C. Allergy to extensively hydrolyzed cow's milk proteins in infants: safety and duration of amino acid-based formula. J Pediatr 2002; 141: 271-3.

24. Hill DJ, Murch SH, Rafferty K, et al. The efficacy of amino acid based formulas in relieving the symptoms of cow's milk allergy: a systematic review. Clin Exp Allergy 2007; 6: 808-22.

25. Wang J. Management of the patient with multiple food allergies. Curr Allergy Asthma Rep 2010; 10: 271-7.

26. Kaczmarski M, Wasilewska J, Lasota M. Hypersensitivity to hydrolyzed cow's milk protein formula in infants and young children with atopic eczema/dermatitis syndrome with cow's milk protein allergy. Rocz Akad Med Bialymst 2005; 50: 274-8.

27. Klemola T, Vanto T, Juntunen-Backman K, et al. Allergy to soy formula and to extensively hydrolyzed whey formula in infants with cow's milk allergy: a prospective, randomized study with a follow-up to the age of 2 years. J Pediatr 2002; 140: 219-24.

28. Kaczmarski M, Matuszewska E, Wasilewska J. Double blind placebo controlled food challenge - why? when? and whom? Act Pneumol Allergol Pediatr 2005; 9: 66-9.

29. Wang J. Management of the patient with multiple food allergies. Curr Allergy Asthma Rep 2010; 10: 271-7.

30. Clein NW. Cow's milk allergy in infants. Ann Allergy 1951; 9: 195-204.

31. Gerrard JW, Lubos MC, Hardy LW, et al. Milk allergy: clinical picture and familial incidence. Can Med Assoc J 1967; 97: 780-5.
32. Hill DJ, Firer MA, Ball G, Hosking CS. Recovery from milk allergy in early childhood. Acta Pediatr Scand 1979; 68: 377-82.

33. Kaczmarski M. Comparative clinical and laboratory studies in primary malabsorption syndrome in children caused by cow's milk protein and gluten intolerance. Pol Tyg Lek 1982; 37: 1535-7.

34. Husby S, Koletzko S, Korponay-Szabó IR, et al. ESPGHAN Working Group on Coeliac Disease Diagnosis, ESPGHAN Gastroenterology Committee. European Society for Pediatric Gastroenterology, Hepatology, and Nutrition guidelines for the diagnosis of coeliac disease. J Pediatr Gastroenterol Nutr 2012; 54: $136-60$

35. Hill DJ, Firer MA, Shelton MJ, Hosking CS. Manifestations of milk allergy in infancy: clinical and immunologic findings. J Pediatr 1986; 109: 270-6.

36. Fogg MI, Spergel JM. Management of food allergies. Expert Opin Pharmacother 2003; 4: 1025-37.

37. Wang J, Sampson HA. Food allergy. J Clin Invest 2011; 3: 827-35.

38. Burks AW, Tang M, Sicherer S, et al. ICON: food allergy. J Allergy Clin Immunol 2012; 129: 906-20.

39. Muñoz-Furlong A, Sampson HA. Fatalities due to anaphylactic reactions to foods. J Allergy Clin Immunol 2001; 107: 191-3.

40. Branum AM, Lukacs SL Food allergy among U.S. children: trends in prevalence and hospitalizations. NCHS 2008; 10: 1-8.

41. Sampson HA. Utility of food-specific IgE concentrations in predicting symptomatic food allergy. J Allergy Clin Immunol 2001; 107: 891-6.

42. Sampson HA. Food anaphylaxis. Br Med Bull 2000; 56: 925-35.

43. Wang J, Sampson HA. Treatments for food allergy: how close are we? Immunol Res 2012; 54: 83-94.

44. Bock SA, Muñoz-Furlong A, Sampson HA. Fatalities due to anaphylactic reactions to foods. J Allergy Clin Immunol 2001; 107: 191-3.

45. Boyano-Martínez T, García-Ara C, Pedrosa M, et al. Accidental allergic reactions in children allergic to cow's milk proteins. J Allergy Clin Immunol 2009; 123: 883-8.

46. Celik-Bilgili S, Mehl A, Verstege A, et al. The predictive value of specific immunoglobulin E levels in serum for the outcome of oral food challenges. Clin Exp Allergy 2005; 3: 268-73.

47. Hill DJ, Murch SH, Rafferty K, et al. The efficacy of amino acidbased formulas in relieving the symptoms of cow's milk allergy: a systematic review. Clin Exp Allergy 2007; 6: 808-22.

48. Wang J. Management of the patient with multiple food allergies. Curr Allergy Asthma Rep 2010; 10: 271-7.

49. Kaczmarski M, Żur E, Kondej-Muszyńska K. Therapeutic and nutritional applications of amino acid-based elemental formulas in children with food allergies: a preliminary report. Post Dermatol Alergol 2012; 29: 86-93.

50. Ramesh S. Food allergy overview in children. Clin Rev Allergy Immunol 2008; 34: 217-30.

51. Aalberse RC. Assessment of allergen cross-reactivity. Clin Mol Allergy 2007; 5: 2.

52. van Ree R. Clinical importance of nonspecific lipid transfer proteins as food allergens. Biochem Soc trans 2002; 30: 910-3.

53. Bohle B, Vieths S. Improving diagnostic tests for food allergy with recombinant allergens. Methods 2004; 32: 292-9.

54. Wöhrl S, Vigl K, Zehetmayer S, et al. The performance of a component-based allergen-microarray in clinical practice. Allergy 2006; 61: 633-9.

55. Chapman MD, Smith AM, Vailes LD, et al. Recombinant allergens for diagnosis and therapy of allergic disease. Allergy Clin Immunol 2000; 106: 409-18.

56. Bijli KM, Singh BP, Sridhara S, et al. An investigation of crossreactive allergens and antigens of Imperata cylindrical using 
Western Blotting and ELISA inhibition. ACI Internation 2002; 15: 62-7.

57. Eigenmann PA, Beyer K, Wesley Burks A, et al. New visions for food allergy: an iPAC summary and future trends. Pediatr Allergy Immunol 2008; 19: 26-39.

58. García BE, Gamboa PM, Asturias JA, et al. Guidelines on the clinical usefulness of determination of specific immunoglobulin E to foods. I Investig Allergol Clin Immunol 2009; 19: 423-32.

59. Söderström L, Lilja G, Borres MP, Nilsson C. An explorative study of low levels of allergen-specific IgE and clinical allergy symptoms during early childhood. Allergy 2011; 66: 1058-64.

60. Cudowska B, Kaczmarski M. Atopy patch test in the diagnosis of food allergy in children with gastrointestinal symptoms. Adv Med Sci 2010; 55: 153-60.

61. Asero R, Ballmer-Weber BK, Beyer K, et al. IgE-mediated food allergy diagnosis: current status and new perspectives. Mol Nutr Food Res 2007; 51: 135-47.

62. Crocard AD, Ennis M. Basophil histamine release test in the diagnosis of allergy and asthma. Clin Exp Allergy 2001; 31: 345-50.

63. Siriganian PS, Hook WA, Zinsser FU, et al. Monoclonal antibodies defining epitopes on human IgE. Mol Immunol 1991; 28: 631-9.

64. Nolte H, Stonn K, Schirtz O. Diagnostic value of a glass fibrebased histamine analysis for testing in children. Allergy 1990; 45: 1-11.

65. Wöhrl S, Vigl K, Zehetmayer S, et al. The performance of a component-based allergen-microarray in clinical practice. Allergy 2006; 61: 633-9.

66. Borres MP, Ebisawa M, Eigenmann PA. Use of allergen components begins a new era in pediatric allergology. Pediatr Allergy Immunol 2011; 22: 454-61.

67. López-Expósito I, Chicón R, Belloque J, et al. In vivo methods for testing allergenicity show that high hydrostatic pressure hydrolysates of beta-lactoglobulin are immunologically inert. J Dairy Sci 2012; 95: 541-8.

68. Bohle B, Vieths S. Improving diagnostic tests for food allergy with recombinant allergens. Methods 2004; 32: 292-9.

69. Fiocchi A, Bouygue GR, Albarini M, Restani P. Molecular diagnosis of cow's milk allergy. Curr Opin Allergy Clin Immunol 2011; 11: 216-21. 